\title{
CLÁUSULAS ABUSIVAS EN LA CONTRATACIÓN AGRÍCOLA. ALTERNATIVAS DE CONTROL EN EL DERECHO CHILENO
}

\author{
UNFAIR TERMS IN AGRICULTURAL CONTRACTS. \\ ALTERNATIVES FOR ITS REGULATION IN CHILEAN LAW
}

RODRIGO MOMBERG URIBE *

\section{RESUMEN}

El trabajo analiza la problemática de las cláusulas abusivas presentes en la contratación agrícola, en particular, aquellas que son impuestas al productor agrícola por sus compradores. Luego de examinar los factores que influyen en la posición de desventaja que afecta, generalmente, al productor agrícola en la cadena agroalimentaria, se exponen las inicitivas que a nivel europeo han tratado el problema, para posteriormente analizar si el derecho positivo chileno ofrece alternativas para el control de estas cláusulas.

Palabras clave: Contratos agrícolas, Contratos de adhesión, Cláusulas abusivas, Revisión del contrato, Competencia desleal, Estatuto de la pequeña y mediana empresa.

\footnotetext{
* Abogado, Universidad Austral de Chile. LLM in European Private Law, Universidad de Utrecht, Países Bajos. Doctor en Derecho, Universidad de Utrecht, Países Bajos. Profesor de Derecho Civil, Pontificia Universidad Católica de Valparaíso, Valparaíso, Chile. Correo electrónico: rodrigo. momberg@pucv.cl. ORCID: https://orcid.org/0000-0002-4774-4256.

** Este artículo forma parte del Proyecto Fondecyt Regular $\mathrm{N}^{\circ} 1181212$, del cual el autor es coinvestigador responsable.

Artículo recibido el 19 de febrero de 2021 y aceptado para su publicación el 25 de junio de 2021.
} 


\section{ABSTRACT}

This paper analyses the problem of unfair terms in contract farming, with regard to those imposed on farmers or food producers by their buyers. After the examination of the causes of the disadvantaged position that generally affects the agricultural producer in the agri-food supply chain, and the European initiatives dealing with this problem, the paper analyzes whether Chilean positive law offers alternatives for the control of these clauses.

Keywords: Contract farming, Adhesion contracts, Unfair terms, Contract revision, Unfair competition, Statute of small and medium-sized companies.

\section{INTRODUCCIÓN}

La cadena de suministro agrícola y alimentario es especialmente compleja. En ella intervienen productores, intermediarios, distribuidores, exportadores, etc. Por lo mismo, esta cadena contempla procesos de producción, de transformación y comercialización, entre otros. La interacción entre los agentes que intervienen en ella se materializa en relaciones contractuales de diversa naturaleza: de intercambio (compraventa y suministro), de financiamiento (préstamos directos), de garantía (cláusulas penales, prendas, hipotecas), de transferencia tecnológica (know how, licencias), etc.

En este trabajo, se analizan ciertas problemáticas que pueden afectar al primer eslabón contractual de dicha cadena, es decir, la relación que existe entre el productor agrícola y su comprador, quien posteriormente introducirá los bienes a la cadena productiva para su transformación o posterior comercialización.

En esta etapa de la cadena de suministro, se han identificado problemas de desequilibrios importantes en el poder negociación entre proveedores y compradores, donde típicamente los segundos constituyen la parte fuerte o aventajada en la relación contractual. Esto puede llevar a la imposición de cláusulas especialmente gravosas para los productores, que impliquen un desequilibrio grave en los derechos y obligaciones de las partes, transfiriendo la mayor parte, o incluso todo el riesgo económico, exclusivamente al 
productor agrícola. ${ }^{1}$

Para el análisis de estas cuestiones, el artículo se estructura de la siguiente manera. En primer lugar, se explican las causas y problemas de abusividad contractual que pueden presentarse en la contratación entre productores agrícolas y sus compradores, con especial referencia a las iniciativas que en esta materia se han adoptado a nivel de la Unión Europea. En segundo lugar, se presentan las alternativas que la legislación chilena ofrece para la regulación de las cláusulas abusivas en contratos celebrados entre profesionales, explicando su procedencia respecto a aquellos objeto de esta trabajo. En tercer lugar, se exponen los problemas que presentan estas alternativas, planteando posibles soluciones a ellos. A continuación, como es usual, el trabajo finaliza con algunas conclusiones.

\section{PRÁCTICAS COMERCIALES DESLEALES EN LA CADENA AGROALIMENTARIA. DIAGNÓSTICO E INICIATIVAS EUROPEAS}

Como se indicó, la cadena agroalimentaria tiene como característica su especial complejidad, tanto desde la perspectiva de la multiplicidad de sujetos que intervienen en ella, como de las relaciones contractuales que vinculan a dichos sujetos. Una definición ilustrativa de la cadena agroalimentaria la entrega el artículo 5 a) de la Ley española 12/2013, de 2 de agosto, de Medidas para mejorar el funcionamiento de la cadena alimentaria, que la conceptualiza como "el conjunto de actividades que llevan a cabo los distintos operadores que intervienen en la producción, transformación y distribución de alimentos o productos alimenticios, excluyendo las actividades de transporte y de la hostelería y la restauración".

La relación contractual que da a origen a dicha cadena es la que se genera entre el productor agrícola y el empresario o profesional comprador (en adelante, solo "el comprador"). Esta primera relación contractual se concreta generalmente en un contrato de compraventa o de suministro de productos agrícolas. ${ }^{2}$ No obstante, especialmente cuando se trata de productos

\footnotetext{
${ }^{1}$ Véase la Directiva (UE) 2019/633 de 17 de abril de 2019, del Parlamento Europeo y del Consejo de Europa, relativa a las prácticas comerciales desleales en las relaciones entre empresas en la cadena de suministro agrícola y alimentario (en adelante, la Directiva 2019/633); y UNIDROIT, FAO y FIDA, Guía jurídica sobre agricultura por contrato, UNIDROIT/FAO/FIDA, 2017, Roma (en adelante, la Guía UNIDROIT).

${ }^{2}$ La Ley No20.797, sobre Registro Voluntario de Contratos Agrícolas, define producto agrícola como
} 
dirigidos a mercados externos, estos contratos contienen otras prestaciones, por ejemplo, relativas a transferencia tecnológica y financiamiento. Ello los hace más complejos que una simple compraventa en que basta con entregar la cosa por una parte y pagar el precio por la otra. ${ }^{3}$

La atención de la doctrina y la legislación ha estado puesta en dos aspectos de tales contratos. Primero, su formalización, por medio de lo que se conoce como "agricultura por contrato" o contract farming, cuyo objetivo principal es incentivar la certeza jurídica para el productor agrícola respecto a los términos y exigibilidad de los contratos que celebra. El segundo aspecto, del cual se ocupa este trabajo, está relacionado con las hipótesis que resultan en la imposición, por parte de los compradores, de cláusulas excesivamente desequilibradas o abusivas en perjuicio del productor agrícola.

Este problema está asociado a la dependencia económica que puede presentar el productor agrícola respecto de su comprador, lo cual puede, a su vez, generar asimetrías en el poder de negociación, y con ello situaciones de abuso contractual. Esta dependencia económica puede tener su origen tanto en fallas de mercado, por ejemplo, concentración del poder adquisitivo en uno o pocos sujetos, pero también puede responder a causas particulares de la relación entre ambos contratantes, como en los casos de proveedores especializados cuyos productos sólo interesan o sirven a una empresa adquirente, o en caso que el comprador además provea tecnología o financiamiento al proveedor. ${ }^{4}$ Lo mismo sucede en situaciones en que la negativa a contratar puede significar para una empresa quedar excluida de hecho del mercado correspondiente, o perder inversiones iniciales significativas, lo que implica que le sea imposible económicamente abandonar la relación comercial desleal o abusiva que le impone su contraparte. ${ }^{5}$

Asimismo, si bien las empresas que se dedican a procesar o comercializar productos agrícolas pueden diversificar su riesgo celebrando contratos con múltiples productores, es habitual que estos últimos no

\footnotetext{
"el que proviene directamente de la agricultura, esto es, aquella materia prima de origen vegetal o animal obtenida del cultivo de la tierra o de la ganadería, sea que se encuentre cosechada o pendiente". ${ }^{3} \mathrm{Al}$ efecto, véase en la Guía UNIDROIT, cit. (n. 1), el Capítulo sobre obligaciones de las partes, pp. 85-142.

${ }^{4}$ Daskalova, Victoria, "The New Directive on Unfair Trading Practices in Food and EU Competition Law: Complementary or Divergent Normative Frameworks?", Journal of European Competition Law \& Practice, 2019, Vol. 10, No. 5, p. 285.

${ }^{5}$ Comisión Europea, Libro Verde sobre las prácticas comerciales desleales en la cadena de suministro alimentario y no alimentario entre empresas en Europa, Bruselas, 31.1.2013 COM (2013) 37 final, p. 6-7 (en adelante, el Libro Verde).
} 
puedan hacer lo mismo, vendiendo su producción completa a un solo comprador, lo que limita sus posibilidades de celebrar un nuevo contrato si dicho contrato no se cumple o termina anticipadamente. ${ }^{6}$ Esta es una situación que puede afectar especialmente a los productores agrícolas de menor tamaño (PYMES), quienes generalmente tienen un mercado limitado en donde comercializar sus productos, con pocos compradores, y que por la naturaleza perecible y de corta duración de los bienes que comercializan, se ve imposibilitados de renegociar contratos ya celebrados o de buscar nuevas alternativas comerciales ante la premura del tiempo para vender su producción. ${ }^{7}$

En definitiva, si bien los problemas de abusividad contractual que pueden presentarse entre productores agrícolas y compradores, pueden tener su origen en fallas estructurales del mercado, ámbito propio del derecho que regula la libre competencia, ellas pueden también tener causas que no van más allá de la relación particular de que se trate. Es por esto que la mejor opción parece ser que la regulación de estas prácticas no sólo se haga cargo de los supuestos de fallas de mercado, sino también de los problemas que puedan surgir, sin que exista una falla de mercado propiamente tal, en el marco de una relación contractual particular, por medio de la regulación más general de prácticas comerciales desleales.

Por ello, no es extraño que los problemas relacionados con las prácticas comerciales y contractuales desleales en la cadena agroalimentaria hayan sido objeto de la preocupación de las instituciones de la Unión Europea hace algunos años.

Entre las iniciativas se cuenta el Grupo de Alto Nivel sobre la Competitividad de la Industria Agroalimentaria, bajo el patrocinio de la Comisión Europea. ${ }^{8}$ El trabajo de dicho Grupo sirvió de base para la Comunicación de la Comisión "Mejorar el Funcionamiento de la Cadena Alimentaria en Europa", en la cual se planteaban como objetivos, entre otros, la preparación de modelos de contrato de utilización voluntaria, y la evaluación de las prácticas contractuales desleales en el mercado interior, con el propósito de proponer las medidas comunitarias necesarias para abordar este tipo de prácticas. ${ }^{9}$

\footnotetext{
${ }^{6}$ Guía UNIDROIT, cit. (n. 1), p. 9.

${ }^{7}$ Comisión Europea, Libro Verde, cit. (n. 5), p. 7.

${ }^{8}$ Creado mediante Comisión Europea, Decisión de la Comisión 2008/359/CE, de 28 de abril de 2008.

${ }^{9}$ Comisión Europea, Comunicación de la Comisión "Mejorar el funcionamiento de la cadena alimentaria
} 
A partir de dicha Comunicación, se creó el "Foro de Alto Nivel sobre la Mejora del Funcionamiento de la Cadena Alimentaria". ${ }^{10}$ Uno de los grupos de trabajo implementado por este Foro tuvo como propósito analizar las prácticas contractuales entre empresas en la cadena agroalimentaria. El trabajo de este grupo se materializó en la denominada Supply Chain Initiative, instancia que publicó el documento "Relaciones verticales en la cadena alimentaria: Principios de buenas prácticas", donde se plantean una serie de principios que deberían guiar las relaciones contractuales en la cadena agroalimentaria, de manera de evitar que se produzcan situaciones de abuso de un agente económico sobre otro. Entre estos destacan el respeto por la libertad contractual de la contraparte, el deber de comportarse de buena fe y con diligencia profesional, la transparencia de los contratos que celebren y la necesidad que cada parte asuma sus propios riesgos empresariales. ${ }^{11}$

Además, el documento ilustra tales principios con ejemplos de prácticas leales y desleales, como la imposición de condiciones generales que contengan cláusulas abusivas, el término inoportuno e injustificado de la relación comercial, la transferencia de riesgos injustificados o desproporcionados y la imposición de la compra de productos o servicios conexos a la relación contractual. Cabe destacar que, de acuerdo con la Comisión Europea, a comienzos de 2013, ocho de las once organizaciones anunciaron su intención de empezar a aplicar los principios de prácticas leales recomendados en el documento de manera voluntaria.

Un paso significativo en el establecimiento de normas comunes a nivel europeo, fue la publicación por la Comisión del ya mencionado "Libro Verde sobre las prácticas comerciales desleales en la cadena de suministro alimentario y no alimentario entre empresas en Europa". Este Libro Verde contiene un diagnóstico respecto a las prácticas comerciales desleales presentes en este sector de la economía y de la existencia o ausencia de regulación a nivel nacional y europeo, con el objeto de recopilar información y consultar a las partes interesadas sobre esta problemática, para efectos de evaluar y determinar las iniciativas siguientes en esta materia.

Como se señala en el Libro Verde: "Las normas sobre prácticas

en Europa", COM (2009) 591 final.

${ }^{10}$ Comisión Europea, Decisión de la Comisión 2010/C 210/03, de 30 de julio de 2010.

${ }^{11}$ Disponible en: The Supply Chain Initiative (Eds.), "Principles of Good Practice in vertical relationships in the Food Supply Chain", documento en línea: https:/www.supplychaininitiative.eu/ about-initiative/principles-good-practice-vertical-relationships-food-supply-chain, consultada: 18 de febrero de 2021. 
comerciales desleales persiguen fundamentalmente un objetivo diferente del de la legislación sobre competencia, puesto que regulan las relaciones contractuales entre empresas especificando las condiciones que, por ejemplo, los proveedores deben ofrecer a los distribuidores, independientemente de los efectos reales o supuestos sobre la competencia en el mercado". ${ }^{12}$

Al Libro Verde siguieron, la Comunicación de la Comisión de 15 de julio de 2014 sobre cómo hacer frente a las prácticas comerciales desleales en la cadena de suministro alimentario entre empresas, ${ }^{13}$ y el Informe de la Comisión de 29 de enero de 2016 sobre las prácticas comerciales desleales en la cadena de suministro alimentario entre empresas. ${ }^{14}$

Las acciones e iniciativas que precedieron a la dictación de la Directiva 2019/633, se identificaron cuatro principales categorías de prácticas comerciales desleales que deberían ser el objetivo de regulación: $:^{15}$

- Traslado indebido o injusto de costos o riesgos de una parte a la otra

- Solicitud de ventajas o beneficios sin una contraprestación correspondiente;

- Introducción de cambios unilaterales o retroactivos que no sean equitativos ni estén especialmente especificados en el contrato;

- Término o amenaza de término del contrato contraria a la buena fe.

El corolario de estas iniciativas fue la dictación de la Directiva (UE) 2019/633 de 17 de abril de 2019, relativa a las prácticas comerciales desleales en las relaciones entre empresas en la cadena de suministro agrícola y alimentario (en adelante, la Directiva 2019/633), la cual su artículo $1^{\circ}$ establece que su objeto es, "luchar contra las prácticas que se apartan manifiestamente de las buenas conductas comerciales, son contrarias a la buena fe y a la lealtad comercial y se imponen unilateralmente por una de las partes a la otra".

Para ello, la Directiva establece una lista mínima de prácticas comerciales desleales prohibidas en las relaciones entre compradores y

\footnotetext{
${ }^{12}$ Comisión Europea, Libro Verde, cit. (n. 5), p. 12.

${ }^{13}$ Comisión Europea, Comunicación de la Comisión de 15 de julio de 2014 sobre cómo hacer frente a las prácticas comerciales desleales en la cadena de suministro alimentario entre empresas, COM (2014) 472 final.

${ }^{14}$ Comisión Europea, Informe de la Comisión de 29 de enero de 2016 sobre las prácticas comerciales desleales en la cadena de suministro alimentario entre empresas, COM (2016) 32 final.

${ }^{15}$ Comisión Europea, Informe de la Comisión al Parlamento Europeo y al Consejo sobre las prácticas comerciales desleales en la cadena de suministro alimentario entre empresas, Bruselas, 29.1.2016 COM (2016) 32 final, p. 5.
} 
proveedores en la cadena de suministro agrícola y alimentario. Al efecto, se establece la prohibición absoluta de ciertas prácticas comerciales (artículo 3.1) y la prohibición relativa, sujeta a requisitos de transparencia, de otras (artículo 3.2). Cabe destacar que no todas las prácticas dicen relación con el establecimiento de cláusulas abusivas, sino también con conductas desleales "de hecho" que realiza comprador sin perjuicio o a pesar de la existencia de un contrato.

Asimismo, en cuestiones fuera del análisis que se efectúa en este trabajo, la Directiva regula también materias relacionadas a las autoridades administrativas encargadas, a nivel de los estados miembros, de controlar el cumplimiento de las prohibiciones que establece.

\section{UNA MIRADA A LA PRÁCTICA CONTRACTUAL. ALGUNAS CLÁU- SULAS COMUNES EN LOS CONTRATOS AGRÍCOLAS}

Existe una tendencia creciente hacia formalización de las relaciones contractuales en el sector agrícola chileno (la ya mencionada "agricultura por contrato"), especialmente en sectores vinculados a la producción de productos agrícolas destinados a la exportación. ${ }^{16}$

Un hito importante a este respecto fue la creación, por la Ley N 20.797 de 19 de diciembre de 2014 y su Reglamento (Decreto 149 de 2016 del Ministerio de Economía, Fomento y Turismo), del Registro Voluntario de Contratos Agrícolas. El objetivo principal la ley, según su artículo $1^{\circ}$, es establecer un sistema de inscripción voluntaria del contrato de compraventa de productos agrícolas en un registro público, nacional y único, que se aplica a los contratos agrícolas con entrega a plazo que consten por escrito, siempre que sea la primera transacción de los productos. Por su parte, el Mensaje del proyecto de ley expresa que la creación del registro voluntario tiene por finalidad principal brindar mayor certeza jurídica a la agricultura por

\footnotetext{
${ }^{16}$ La Oficina de Estudios y Políticas Agrarias (ODEPA) del Ministerio de Agricultura ha señalado que $48 \%$ de los productores que destinan su producción a la exportación utilizan la agricultura por contrato, en comparación con sólo un 3\% de aquellos productores que destinan su producción al mercado doméstico. Asimismo, el estudio indica que al menos 50\% de la producción de las plantas procesadores agroindustriales utiliza la agricultura por contrato para la adquisición de sus materias primas. Véase CERPA, Javier y FARÍAS, Claudio, "Uso de contratos en la agroindustria nacional para hortalizas", Oficina de Estudios y Políticas Agrarias - ODEPA, Ministerio de Agricultura, noviembre de 2020, disponible en: https://www.odepa.gob.cl/publicaciones/articulos/uso-de-contratos-en-laagroindustria-nacional-para-hortalizas.
} 
contrato, dando publicidad a los contratos agrícolas y declarando su carácter oponible a terceros si las partes lo hubieren inscrito voluntariamente.

Un examen de los contratos inscritos en el mencionado Registro devela la utilización repetida de ciertas cláusulas que podrían estimarse como abusivas, o al menos, excesivamente favorables a los intereses de los compradores de productos agrícolas. Por ejemplo, y sin que la enumeración sea exhaustiva, en tales contratos es usual encontrar cláusulas que establecen:

a) La determinación unilateral de conformidad de los productos vendidos por la parte compradora, así como de las consecuencias de la no conformidad. ${ }^{17}$

b) La modificación de la regla del artículo 1550 del Código Civil, trasladando el riesgo de la cosa vendida al vendedor, en algunos casos incluso hasta algún hecho posterior a la tradición del producto vendido. ${ }^{18}$

c) La exoneración de responsabilidad o extinción de las obligaciones del comprador por incumplimiento en caso de eventos considerados como fuerza mayor, sin que exista una cláusula recíproca para las obligaciones del productor agrícola. ${ }^{19}$

d) La exoneración de responsabilidad o extinción de las obligaciones del comprador por cambios de circunstancias que afecten sus obligaciones, sin que exista una cláusula recíproca para las obligaciones del productor

\footnotetext{
${ }^{17}$ Así, por ejemplo, la cláusula que establece que: "La determinación de la calidad y la aprobación de su embalaje corresponderán exclusivamente a la compradora. En el evento de detectarse que la fruta no cumpla con uno o más de los requisitos señalados, la compradora procederá a rechazar la totalidad del envío o una partida correspondiente"; y aquella que señala: "La fruta que no cumpla con las condiciones establecidas en esta cláusula se considerará excluida de este contrato y será destinada al mercado interno y cualquier gasto adicional, merma y /o pérdida de la fruta como consecuencia del incumplimiento de la obligación a que se refiere este artículo, será de responsabilidad o cargo exclusivo del vendedor".

${ }^{18}$ En este sentido, la cláusula donde se pacta que: "Las Partes declaran entender y consentir expresamente, que la tradición de la fruta materia y objeto del presente contrato se perfeccionará al momento de la entrega a conformidad del Comprador. Sin perjuicio de lo anterior, la pérdida o deterioro de la fruta hasta la aceptación conforme del Recibidor o Importador en destino, será siempre de cargo de la Vendedora".

${ }^{19}$ Así, la cláusula que establece que "Si durante la vigencia de este contrato, ocurren situaciones, tales como revolución, guerra, inundación, boicot internacional, huelga, actos terroristas o restricciones a las importaciones a los países de destino o cierre de dichas importaciones, sean parciales o definitivas, o surgieren notorias anomalías en él o los mercados de destino, el presente contrato se resolverá de pleno derecho, sin derecho a indemnización de perjuicios para ninguna de las partes. Si la condición resolutoria antes expresada, aconteciere en forma previa a la tradición de la fruta vendida, la compradora no tendrá obligación alguna de recibirla". En términos similares, la cláusula que señala que "Las partes firmantes acuerdan que en caso de ocurrir hechos, ya sea en Chile o en el extranjero, no imputables a "la compradora", que le impidan efectuar la exportación de la fruta materia de este Contrato, se producirá, ipso facto, sin necesidad de aviso alguno, la suspensión de las obligaciones que "la compradora" adquiere por este contrato".
} 
agrícola. $^{20}$

e) Mandatos irrevocables para la liquidación final que por concepto de precio deberá pagarse por la compradora al productor agrícola. ${ }^{21}$

f) La renuncia al plazo de 30 días, establecido por la Ley $N^{\circ} 21.131$, para el pago de facturas emitidas por el vendedor.

El análisis revela la existencia en tales contratos de las prácticas abusivas a que se ha hecho referencia en los apartados anteriores, esto es, cláusulas excesivamente desequilibradas en perjuicio del productor agrícola, en que se le transfieren todos o la gran mayoría de los riesgos comerciales y económicos del negocio. A continuación se exponen las alternativas que eventualmente ofrece el derecho nacional para la corrección y control de estas prácticas.

\section{ALTERNATIVAS DE REGULACIÓN PARA LAS CLÁUSULASABUSIVAS EN LOS CONTRATOS AGRÍCOLAS EN LA LEGISLACIÓN CHILENA}

El problema de las cláusulas abusivas en contratos celebrados entre profesionales, y las justificaciones para su regulación, son temas que han sido tratados extensamente en la doctrina comparada y nacional, a la cual nos remitimos. ${ }^{22}$ Para efectos de este trabajo, la cuestión relevante es que en

\footnotetext{
${ }^{20}$ Por ejemplo, la cláusula que indica que "Las partes están de acuerdo en que las estipulaciones relativas al precio de la compraventa, han sido pactadas teniendo presente condiciones normales de funcionamiento de los mercados internacionales, considerados en temporadas anteriores; y que cualquier cambio sustancial en las condiciones de mercado y/o el eventual cierre de dichos mercados a este tipo de productos, o cualquier hecho ajeno a la compradora que no permita comercializar la fruta a lo menos a un valor que permita pagar el precio que se pacta en este contrato, altera y modifica substancialmente los efectos del Contrato, e impedirá su cumplimiento en forma absoluta, razón por la cual las partes convienen que ese hecho es igualmente asimilado como fuerza mayor y le es aplicable lo señalado en el primer párrafo de esta cláusula. Lo anterior, junto con liberar a la compradora del cumplimiento de las obligaciones de este contrato, obliga a las partes a modificar sus estipulaciones con el propósito de que pueda surtir efectos adecuados a las nuevas condiciones, y en caso de no haber acuerdo entre las partes al respecto, el presente contrato terminará en forma inmediata".

${ }^{21}$ En este sentido, la cláusula que dispone que "La compradora queda expresa e irrevocablemente facultada para deducir de la liquidación final todos los anticipos que se hayan entregados según lo estipula este contrato, más su intereses y recargos pactados, como así mismo, cualquier otra suma de dinero, valores o efectos de comercio que por cualquier concepto "la compradora" haya incurrido para el proceso de exportación".

${ }^{22} \mathrm{Al}$ efecto, véase Hesselink, Martjin, "Unfair terms in contracts between businesses", en: Schulze, R. y Stuyck, J. (Eds.), Towards a European Contract Law, Sellier, Munich, 2011; Morales, María Elisa; Mendoza, Pamela; Munita, Renzo, "Cláusulas abusivas entre empresas. Evolución en los principales sistemas de derecho comparado" Vniversitas, 2020 (69), y MoMBERG, Rodrigo, "Las personas jurídicas
} 
el derecho chileno no existe una regulación sistemática que se ocupe de este problema. Tampoco la Ley No 20.797, que creó el Registro Voluntario de Contratos Agrícolas, abordó esta materia.

Por ello, una primera aproximación podría llevar a concluir que las cuestiones relativas a cláusulas abusivas se limitan, en nuestra legislación, a los contratos celebrados entre proveedores y consumidores (Párrafo $4^{\circ} \mathrm{del}$ Título II de la Ley Nº19.496).

Sin embargo, de manera inorgánica se han ido incorporando hipótesis legales que dicen relación con el establecimiento de cláusulas abusivas en contratos celebrados entre profesionales. ${ }^{23}$ A continuación se examinarán algunas de ellas, analizando su procedencia respecto a la situación del productor como parte débil en la contratación agrícola, protegiéndolo ante las prácticas comerciales desleales de sus compradores.

\section{1.- La ley $N^{\circ} 20.416$ o Estatuto PYME}

La Ley No20.416, que fijó normas especiales para las empresas de menor tamaño, también conocida como "Estatuto PYME", fue dictada con el objeto de facilitar el desenvolvimiento de las empresas de menor tamaño, mediante la adecuación y creación de normas regulatorias que rijan su iniciación, funcionamiento y término, en atención a su tamaño y grado de desarrollo (artículo 1). Para cumplir con dicho objeto, la ley regula una amplia variedad de materias: administrativas (procedimientos para la dictación de reglamentos y normas de carácter general, transparencia en procedimientos de fiscalización, otorgamiento de permisos de funcionamiento, normas sanitarias, acuerdos de producción limpia), de insolvencia (reorganización o cierre de micro y pequeñas empresas en crisis) y contractuales (ampliación de la LPC a micro y pequeñas empresas). Además, se crea el Consejo Nacional Consultivo de la Empresa de Menor Tamaño, asesor del Ministerio

como consumidores", en: FERrante, A. (Dir.), Venta y protección del consumidor, Thomson Reuters, 2019, p. 43-62.

${ }^{23}$ Sobre esta cuestión, véase MomBERG, Rodrigo, "El control de las cláusulas abusivas en contratos entre profesionales en el derecho chileno", en: Elorriaga, F. (Ed.), Estudios de Derecho Civil XV, Thomson Reuters, Santiago, 2021, p. 623-633. Por otra parte, se ha también planteado aisladamente que a partir de la noción de objeto ilícito, podría entenderse que existe una norma implícita en el Código Civil que permite alegar la nulidad absoluta de aquellas cláusulas que, en un contrato de adhesión, generan un desequilibrio importante en los derechos y obligaciones de las partes. Al efecto, véase CAMPOS, Sebastián, Control de contenido y régimen de ineficacia de las cláusulas abusivas, Thomson Reuters, Santiago, 2019, pp. 303-319. 
de Economía, Fomento y Reconstrucción.

En virtud de lo dispuesto en el art. 9 de dicha ley, se otorga a las micro y pequeñas empresas, es decir, aquellas con menos de 2400 UF o 25.000 UF de ingreso anual en el último año calendario, protección en su rol de consumidoras, extendiendo el ámbito de aplicación de la ley 19.496 a los actos y contratos que estas pequeñas empresas celebren con sus proveedores. ${ }^{24}$ Esta extensión de la aplicación de la ley 19.496 implica, entre otras cosas, que los contratos de adhesión que las micro y pequeñas empresas celebren con sus proveedores, quedan sujetos al control de abusividad de los arts. 16 y siguientes de la LPC. $^{25}$

Una primera lectura podría llevar a la conclusión que, tratándose de pequeños productores agrícolas, que califiquen como micro o pequeñas empresas, la extensión del ámbito de aplicación del régimen sobre cláusulas abusivas de la Ley $\mathrm{N}^{\circ} 19.496$ podría ser un medio eficaz para protegerlos en los contratos que celebren con sus compradores.

Sin embargo, se trata de una conclusión errada. Al menos para la hipótesis objeto de este trabajo, en que el productor agrícola actúa como proveedor (vende sus productos), no es posible extender el ámbito de aplicación de las normas de la Ley No19.496, ya que la Ley $\mathrm{N}^{\mathrm{o}} 20.146$ requiere que la micro o pequeña empresa celebre un contrato con un proveedor. Es por ello que, al menos por la vía de la Ley 20.416, no es posible otorgar protección al productor agrícola ante eventuales cláusulas

\footnotetext{
${ }^{24} \mathrm{El}$ art. segundo de la ley 20.416 establece que "Son microempresas aquellas empresas cuyos ingresos anuales por ventas y servicios y otras actividades del giro no hayan superado las 2.400 unidades de fomento en el último año calendario; pequeñas empresas, aquellas cuyos ingresos anuales por ventas, servicios y otras actividades del giro sean superiores a 2.400 unidades de fomento y no exceden de 25.000 unidades de fomento en el último año calendario, y medianas empresas, aquellas cuyos ingresos anuales por ventas, servicios y otras actividades del giro sean superiores a 25.000 unidades de fomento y no exceden las 100.000 unidades de fomento en el último año calendario". La misma norma, en sus incisos $7^{\circ}$ y $8^{\circ}$ precisa que: "No podrán ser clasificadas como empresas de menor tamaño aquellas que tengan por giro o actividad cualquiera de las descritas en las letras d) y e) de los números $1^{\circ}$ y $2^{\circ}$ del artículo 20 de la Ley sobre Impuesto a la Renta; aquellas que realicen negocios inmobiliarios o actividades financieras, salvo las necesarias para el desarrollo de su actividad principal, o aquellas que posean o exploten a cualquier título derechos sociales o acciones de sociedades o participaciones en contratos de asociación o cuentas en participación, siempre que, en todos estos casos, los ingresos provenientes de las referidas actividades en conjunto superen en el año comercial anterior un $35 \%$ de los ingresos de dicho período. Tampoco podrán ser clasificadas como tales aquellas empresas en cuyo capital pagado participen, en más de un $30 \%$, sociedades cuyas acciones tengan cotización bursátil o empresas filiales de éstas".

${ }^{25}$ Para otras consecuencias de la extensión del ámbito de aplicación de la LPC a micro y pequeñas empresas, véase MomberG, Rodrigo, "La transformación de la Ley de Protección de los Derechos de los Consumidores en la norma común del derecho de contratos chileno", en Elorriaga, F. (Coord.), Estudios de Derecho Civil VII, Lexis Nexis, Santiago, 2012, pp. 377-391.
} 
abusivas impuestas por su quien adquiere sus productos, ya que justamente en dicho caso, el productor agrícola está actuando como proveedor. ${ }^{26}$

\section{El art. 2 de la ley 19.983, sobre mérito ejecutivo de la factura}

El nuevo art. 2 de la Ley $\mathrm{N}^{\circ} 19.983$, sobre mérito ejecutivo de la factura, modificado por la Ley $\mathrm{N}^{\circ} 21.131$, que estableció el pago a 30 días de tales instrumentos, introducce otra hipótesis de control de cláusulas abusivas en contratos entre profesionales.

Según esta norma, aplicable, según lo establece el art. 1 de la misma ley, a "toda operación de compraventa, de prestación de servicios, o en aquellas que la ley asimile a tales operaciones, en que el vendedor o prestador del servicio esté sujeto a la obligación de emitir factura":

"no producirán efecto alguno las cláusulas o estipulaciones que intenten demorar indebidamente el pago de la factura al vendedor o prestador del servicio. En especial, las cláusulas o estipulaciones que: 1. Otorguen al comprador o beneficiario del servicio la facultad de dejar sin efecto o modificar a su solo arbitrio el contrato, sin requerir del consentimiento previo y expreso del vendedor o prestador del servicio, sin perjuicio de las excepciones que las leyes contemplen.

2. Contengan limitaciones absolutas de responsabilidad que puedan privar al vendedor o prestador del servicio de su derecho de resarcimiento frente a incumplimientos contractuales". ${ }^{27}$

\footnotetext{
${ }^{26}$ Paradojalmente, en este caso podría ser la contraparte del productor agrícola la que se aprovechase de la regulación de la Ley $\mathrm{N}^{\circ} 19.496$, si se trata de una micro o pequeña empresa. Obviamente, si se trata de contratos celebrados por el productor agrícola (que califique como micro o pequeña empresa) con un proveedor, la ley Nº19.496 si recibirá aplicación. Así sucederá, por ejemplo, cuando el productor agrícola adquiera maquinarias u otros insumos para desarrollar su negocio.

${ }^{27}$ Entre las prácticas comerciales que se prohíben absolutamente, y que podrían reflejarse en cláusulas contractuales, la Directiva 2019/633 establece dos casos similares, relativos al término y modificación unilateral del contrato por parte del proveedor. En cuanto al término anticipado del contrato, la letra b) del artículo 3.1 de la Directiva prohíbe "que el comprador cancele un pedido de productos agrícolas y alimentarios perecederos en un plazo tan breve que el proveedor no puede razonablemente esperar encontrar una alternativa para comercializar o utilizar esos productos; una notificación inferior a 30 días se considerará siempre un plazo demasiado breve. Los Estados miembros podrán establecer períodos inferiores a 30 días para sectores específicos y en casos debidamente justificados". Por su parte, la letra c) del mismo artículo se refiere a la modificación unilateral del contrato, prohibiendo "que el comprador modifique unilateralmente los términos del contrato de suministro de productos agrícolas y alimentarios, en lo que se refiere a la frecuencia, método, lugar, calendario o volumen del suministro o la entrega de los productos agrícolas y alimentarios, las normas de calidad, las condiciones de pago o los precios, o en lo que se refiere a la prestación de servicios siempre que estos se mencionan explícitamente en el apartado 2".
} 
Al contrario de lo que sucede con la ley $\mathrm{N}^{\circ} 20.416$, en que que requiere ser la contraparte de un proveedor, esta hipótesis tiene por objeto proteger al vendedor o prestador de un servicio sujeto a la obligación de emitir factura, situación que es justamente la de los productores agrícolas. La norma no restringe su aplicación a las micro o pequeñas empresas, de manera que incluso un productor agrícola que califique como mediana o gran empresa también se ve beneficiado por ella. ${ }^{28}$

\section{El art. 4 i) de la ley 20.169, que regula la competencia desleal}

Otra norma que puede ser útil para controlar eventuales cláusulas abusivas que se impongan a los prodcutores agrícolas es el art. 4 i) de la Ley $\mathrm{N}^{\mathrm{o}} 20.169$, que regula la competencia desleal, que dispone que se considerarán actos de competencia desleal:

"El establecimiento o aplicación de cláusulas contractuales o conductas abusivas en desmedro de los proveedores, el incumplimiento sistemático de deberes contractuales contraídos con ellos o de los plazos dispuestos en la ley $\mathrm{N}^{\mathrm{o}} 19.983$ para el cumplimiento de la obligación de pago del saldo insoluto contenido en la factura".

Al igual que en el caso del artículo 2 de la ley 19.983, esta norma contempla también un supuesto amplio de aplicación subjetiva, ya que sólo exige que el afectado sea un proveedor, sin distinguir, nuevamente, si es una micro, pequeña, mediana o gran empresa, de manera que resulta plenamente aplicable respecto a los contratos de venta celebrados por los productores agrícolas.

La norma establece una causal general de abusividad, que puede considerarse incluso más amplia que la contemplada en el artículo 16 letra g) de la LPC, ya que considera un acto de competencia desleal el "establecimiento o aplicación de cláusulas contractuales (...) abusivas en desmedro de los proveedores". Ello plantea la cuestión sobre los criterios que deberán considerarse para estimar que una cláusula es abusiva en el contexto de un contrato entre profesionales, problema que, junto a otros, se aborda en la siguiente Sección.

\footnotetext{
${ }^{28}$ El inciso tercero del mencionado artículo 2 establece un caso especial de protección para las empresas de menor tamaño definidas en la ley $\mathrm{N}^{\circ} 20.416$, al prohibir los acuerdos de extensión el plazo legal para el pago de las facturas entre dichas empresas y otras de mayor tamaño. La norma agrega que "Excepcionalmente, estos acuerdos podrán pactarse, si el plazo de pago de la factura que exceda el establecido en el inciso primero, es en beneficio de la empresa de menor tamaño acreedora, y solo en aquellos casos que contemplen realización de pruebas, pagos anticipados, parcializados o por avances".
} 


\section{LOS PROBLEMAS DE LA FALTA DE REGULACIÓN SISTÉMICA}

\section{Los sujetos potencialmente beneficiados}

Como se ha explicado en los párrafos precedentes, la Ley $\mathrm{N}^{\circ} 19.496$ (vía art. 9 de la Ley $\mathrm{N}^{\circ} 20.416$ ) no resulta aplicable al supuesto en que la micro o pequeña empresa actúa como proveedor; y, por otra parte, las hipótesis contempladas en las leyes $\mathrm{N}^{\mathrm{o}} 19.983$ y 20.169 reciben aplicación sin importar el tamaño de la empresa.

Ello resulta en que empresas de gran tamaño podrían eventualmente acceder a estos regímenes de protección, incluso cuando su contraparte sea una empresa de menor entidad. Si bien se ha discutido que, al igual que en las relaciones con consumidores, la protección del contratante débil sea el fundamento principal para el control de cláusulas abusivas entre profesionales, no cabe duda que es una cuestión relevante al momento de establecer un sistema adecuado y coherente en esta materia.

Asimismo, tal como se explicó en la Sección 2 de este trabajo, parece ser una situación habitual que en la cadena de suministro agrícola el productor se encuentre en una condición de desventaja estructural frente a sus compradores.

Es por ello que, en materia de contratación agrícola, la citada Directiva 2019/633 adopte como criterio objetivo de protección el volumen de negocios anual del respectivo agente de mercado, expresando el Considerando 14 que: "Un límite superior debe impedir que se conceda protección a agentes que no sean vulnerables, o que lo sean significativamente menos que sus homólogos o competidores más pequeños”. El propósito es proteger a los agentes de la cadena productiva de menor tamaño frente a aquellos de mayor tamaño, los cuales se presume tienen mayor poder de negociación y podrían por ello incurrir en prácticas desleales o abusivas.

Para evitar que la regulación pueda favorecer a una empresa de igual o mayor tamaño que su contraparte, la Directiva establece un mecanismo que asegura siempre la protección del contratante de menor tamaño frente a otro con mayor poder económico.

El artículo 2.2 dispone a este efecto:

“2. La presente Directiva se aplicará a determinadas prácticas comerciales desleales que se producen en relación con las ventas de productos agrícolas y alimentarios por:

a) un proveedor que tenga un volumen de negocios anual de menos 
de 2000000 EUR a un comprador que tenga un volumen de negocios anual de más de 2000000 EUR;

b) un proveedor que tenga un volumen de negocios anual de más de 2000000 y menos de 10000000 EUR a un comprador que tenga un volumen de negocios anual de más de 10000000 EUR;

c) un proveedor que tenga un volumen de negocios anual de más de 10 000000 EUR y menos de 50000000 EUR a un comprador que tenga un volumen de negocios anual de más de 50000000 EUR;

d) un proveedor que tenga un volumen de negocios anual de más de 50000000 EUR y menos de 150000000 EUR a un comprador que tenga un volumen de negocios anual de más de 150000000 EUR;

e) un proveedor que tenga un volumen de negocios anual de más de 150000000 EUR y menos de 350000000 EUR a un comprador que tenga un volumen de negocios anual de más de 350000000 EUR". ${ }^{29}$

De este modo, el sistema establecido por la Directiva asegura que siempre el contratante protegido sea aquella parte que aparece - al menos objetivamente - como más débil frente a la otra. En un sentido similar, la Ley española 12/2013, de medidas para mejorar el funcionamiento de la cadena alimentaria, dispone como uno de sus supuestos de aplicación en su artículo 2.3 c), "Que uno de los operadores tenga una situación de dependencia económica respecto del otro operador, entendiendo por tal dependencia, que la facturación del producto de aquél respecto de éste sea al menos un $30 \%$ de la facturación del producto del primero en el año precedente".

Al establecer criterios objetivos relativos al tamaño de la empresa o de dependencia económica para su aplicación, la legislación europea deja atrás una regulación exclusivamente vinculada al ámbito de la libre competencia (aunque obviamente se complementa con ella), ya que su no se relaciona con el poder o participación de mercado de la empresa respectiva, sino al poder de negociación relativo que la empresa tenga en una transacción específica. ${ }^{30}$

\footnotetext{
${ }^{29}$ Directiva 2019/633, cit. (n. 1).

${ }^{30}$ Ello sin perjuicio que, en la cadena de suministro agrícola y alimentario, ciertas prácticas comerciales desleales puedan ser sistémicas, es decir, sean habituales, afectando a un número importante de sus participantes de manera simultánea. Al efecto, véase Daskalova, Victoria, "Regulating Unfair Trading Practices in the EU Agri-food Supply Chain: a Case of Counterproductive Regulation?", Yearbook of Antitrust and Regulatory Studies, Vol. 2020, 13(21), p. 14.
} 
A falta de estipulación legal expresa, en Chile no podrían restringirse para estos efectos las hipótesis contempladas en las leyes Nº19.983 y 20.169 sólo a casos en que el proveedor agrícola se encuentre en una situación de desventaja objetiva -por su tamaño u otro criterio- frente a su comprador, cuestión que debería subsanarse en una futura regulación. Sin embargo, como se explica en los párrafos que siguen, a partir del tipo de contrato celebrado y del concepto de abusividad, pueden construirse criterios que aseguren que la protección será otorgada exclusivamente al contratante débil o desventajado.

\section{El tipo de contrato}

Las hipótesis contempladas en las leyes $\mathrm{N}^{\circ} 19.983$ y 20.169 no se encuentran restringidas a los contratos de adhesión, lo que implicaría que, en principio, al contrario de lo que sucede en el ámbito del derecho del consumidor, puedan también aplicarse a contratos libremente discutidos.

Si bien puede ser ajustada al tenor literal de la ley, una interpretación que extienda el ámbito de aplicación objetivo de tales normas a los contratos libremente negociados no parece la más adecuada. La razón es simple. En los contratos libremente discutidos, debiera primar la asunción que cada parte ha podido -y debido- cautelar sus propios intereses, y que por tanto, ninguna merece una protección especial, como tampoco corresponde al derecho inmiscuirse en lo pactado. ${ }^{31}$ Además, debe recordarse que estamos en presencia de contratos celebrados entre profesionales, que incluso pueden ser grandes empresas. Esta cuestión fue debatida a propósito de la reforma al Código Civil francés del año 2016. La primera propuesta del Ministerio de Justicia incluía una norma que entregaba al juez la facultad de suprimir una cláusula que crease un desequilibrio significativo entre los derechos y obligaciones de las partes, sin distinguir la naturaleza del contrato. La norma fue criticada duramente por parte importante de la doctrina, y por asociaciones de empresarios y profesionales, por lo que finalmente el texto aprobado restringió el control a los contratos de adhesión en su art. $1171 .^{32}$

\footnotetext{
${ }^{31}$ López, Jorge; Elorriaga, Fabián, Los contratos. Parte general, Thomson Reuters, Santiago, 2017, Sexta Ed. actualizada.

${ }^{32}$ Deshayes, Olivier; Genicon, Thomas; LaITHIER, Yves-María, Réforme du droit des contrats, du régime général et de la preuve des obligations, LexisNexis, Paris, 2016. El artículo 1171 del Código Civil francés dispone "Dans un contrat d'adhésion, toute clause qui crée un déséquilibre significatif entre les droits et obligations des parties au contrat est réputée non écrite. «L'appréciation du déséquilibre
} 
Por otra parte, como se ha reiterado en este trabajo, que el contrato sea celebrado entre profesionales no excluye que uno pueda encontrarse en una posición de dependencia o desventaja respecto de otro, especialmente cuando concurren supuestos de dependencia económica, como sucede habitualmente con el productor agrícola respecto a sus compradores. También se ha señalado en los párrafos anteriores que lo ideal es que tal desventaja se plasme en criterios normativos objetivos, como el tamaño de las empresas que celebran el contrato. Sin embargo, esta no ha sido hasta ahora la alternativa adoptada por el legislador chileno cuando se trata de proteger al proveedor como parte débil de la relación contractual.

Entonces, considerando que no parece adecuado el establecimiento de un control de abusividad cuando el contrato ha sido libremente discutido -lo que presupone la igualdad de los contratantes en su negociación-, ¿Cuál podría ser una interpretación alternativa para las hipótesis de las leyes $\mathrm{N}^{\mathrm{o}} 19.983$ y 20.169 ?

La respuesta viene dada por la distinción entre contratos de adhesión y cláusulas no negociadas. Si bien existen situaciones en que, técnicamente, en estricto rigor, el contrato no puede calificarse como uno de adhesión, ya que algunas de sus disposiciones han sido objeto de negociación, frecuentemente, aquellas que se refieren a los elementos esenciales del mismo, como el precio o algún aspecto de la prestación que debe darse o ejecutarse, el resto de las disposiciones contractuales son impuestas por uno de los contratantes. Estas cláusulas, denominadas cláusulas no negociadas, si bien no referidas a las prestaciones principales convenidas, tendrán o podrán tener gran importancia en el desarrollo de la relación contractual: cláusulas sobre modificación o terminación unilateral, exención o limitación de responsabilidad, multas o penas convencionales, jurisdicción y otras.

En particular, respecto de la cadena de suministro agrícola y alimentario, debe recordarse que las situaciones de abusividad se producen principalmente debido a los problemas de dependencia económica que impiden a los productores negociar las condiciones de los contratos que celebran con los compradores. Se trata de proteger entonces a aquel contratante que, careciendo del poder de negociación necesario, debe aceptar la imposición de cláusulas predispuestas y desproporcionadamente favorables a su contraparte. En otras palabras, el propósito de esta regulación es suplir la libertad o autonomía contractual cuando ella en la práctica no

significatif ne porte ni sur l'objet principal du contrat ni sur l'adéquation du prix à la prestation". 
existe, y "garantizar que el resultado sea similar al que se hubiera alcanzado de haber habido esa autodeterminación, resultado que viene representado por cierta regulación equilibrada de las obligaciones y derechos de los contratantes". ${ }^{33} \mathrm{Si}$ el contrato o la cláusula respectiva ha sido negociada, la regulación legal pierde sentido y deberá primar el acuerdo de las partes.

Siguiendo la distinción entre contratos de adhesión y cláusulas no negociadas, podría por tanto entenderse que la las normas respectivas de las leyes $\mathrm{N}^{\circ} 19.983$ y 20.169 han pretendido regular sólo aquellas cláusulas sobre las cuales no haya existido negociación. Entonces, en el caso de la Ley $N^{\circ} 19.983$, sólo podrán dejarse sin efecto aquellas cláusulas que intenten demorar indebidamente el pago de la factura, las de terminación o modificación unilateral, y las de exención absoluta de responsabilidad, cuando hayan sido impuestas por el cliente o mandante, sin posibilidad que el proveedor haya podido negociarlas ni menos negarse a ellas. La misma interpretación debiese darse a la hipótesis general de la Ley No20.169: deberá igualmente tratarse de cláusulas impuestas al proveedor y no de una que haya sido objeto de negociación entre las partes.

\section{Los criterios para determinar la abusividad}

La hipótesis general contemplada en el artículo 4 i) de la Ley Nº20.169 plantea la pregunta de si el criterio para establecer el carácter abusivo de una cláusula en un contrato entre profesionales, debe ser o no el mismo que el que se utiliza en contratos de consumo.

Hay que recordar que en Chile no existe una definición legal de cláusula abusiva, al contrario de lo que sucede, por ejemplo, en la legislación europea. Sin embargo, se ha estimado que la mencionada letra g) del art. 16 de la Ley No 19.496 puede servir como guía para tal definición. ${ }^{34}$ En concreto, por tanto, la cuestión es determinar si los criterios que ha desarrollado la doctrina y la jurisprudencia para estimar que una cláusula es abusiva en virtud de dicha norma, sirven cuando se trata de contratos celebrados entre profesionales.

La respuesta debe vincularse al fundamento y función del control de

${ }^{33}$ Mato, María Natalia, Cláusulas abusivas y empresario adherente, Agencia Estatal Boletín Oficial del Estado, Madrid, 2017, p. 50.

${ }^{34}$ DE la MAZA, Iñigo, "El control de las cláusulas abusivas y la letra g)", Revista Chilena de Derecho Privado, 2004, Nº1; Momberg, Rodrigo; Pizarro, Carlos, “Art. 16 g)”, en: De la Maza I. y Pizarro, C. (Eds.), La protección de los derechos de los consumidores, Thomson Reuters, Santiago, 2013. 
las cláusulas abusivas. ${ }^{35} \mathrm{Si}$ aceptamos que, en contratos celebrados entre profesionales, la protección de la parte débil -o precisamente, de la libertad contractual de dicha parte- no es el fundamento, o al menos no es el único fundamento, del control de abusividad, habrá que reconocer que el criterio para determinar dicha abusividad no puede ser el mismo que en el caso de los contratos de consumo, donde es justamente la consideración del consumidor como la parte débil o desventajada de la relación contractual la que justifica la intervención en el contrato que celebra con el proveedor.

Las diferencias entre la protección brindada al consumidor y al profesional respecto a las cláusulas abusivas ha sido reconocida ampliamente por la doctrina y el derecho comparado. En este sentido, se ha dicho que "mientras el consumidor lleva a cabo un acto para su uso personal, el empresario adherente está contratando por razón de su negocio, con ánimo de lucro y con una repercusión - más o menos directa- sobre su actividad empresarial. ${ }^{36}$

Es por ello que, además de la protección del contratante débil, el control de las cláusulas abusivas en contratos celebrados entre profesionales encuentra también su fundamento en cuestiones relacionadas con un funcionamiento adecuado y correcto del mercado. Al simplificar el proceso de contratación, los contratos de adhesión y por extensión, las cláusulas no negociadas, cumplen una importante función económica, ya que facilitan el funcionamiento del mercado. Así, quien se enfrenta a un contrato de adhesión lo hace confiando en que quien se lo ofrece no se aprovechará de su posición de predisponente. Si esa confianza es defraudada, se defrauda y afecta no sólo la confianza del contratante particular, sino la confianza en el mercado mismo, lo cual justifica la intervención del legislador. Al sancionarse las cláusulas abusivas, se protege el ethos del mercado, ya que la sociedad será y funcionará mejor si quienes realizan transacciones económicas no son engañados o confundidos por otros actores del mercado. ${ }^{37}$

La diversa-o más amplia- fundamentación del control de las cláusulas abusivas entre profesionales tiene como consecuencia que el criterio general de abusividad no deba ser el mismo que el que se aplica en un contrato celebrado con un consumidor. Esta diferencia ha sido reconocida, por

\footnotetext{
${ }^{35}$ Jansen, Nils, "Section 2: Unfair Contract Terms", en: Jansen, N. y Zimmermann, R. (Eds.), Commentaries on European Contract Laws, Oxford University Press, Oxford, 2018.

${ }^{36}$ Mato, cit. (n. 33), p. 48.

${ }^{37}$ HesselinK, Martjin, cit. (n.22), p. 142.
} 
ejemplo, en el Draft Common Frame of Reference (DCFR) y la propuesta para una Common European Sales Law (CESL), que exigen, para considerar como abusiva una cláusula en un contrato entre profesionales, no sólo que cause un detrimento importante a una de las partes, o un desequilibrio significativo en los derechos y obligaciones del contrato, sino que además, se aparte manifiestamente de las buenas prácticas comerciales, en contra de la buena fe y de la lealtad comercial (art. II.- 9:405 DCFR y art. 86 CESL). ${ }^{38}$ En este sentido, se ha dicho que, en este tipo de contratos, el estándar de abusividad se debiese aplicar con mayor flexibilidad que en materia de consumo, ${ }^{39}$ examinando el contrato en su conjunto y no solamente la cláusula aisladamente, lo que incluso podría implicar tomar en cuenta el precio estipulado, el cual podría responder justamente a ventajas o concesiones reflejadas en otras cláusulas. ${ }^{40}$ Las costumbres y prácticas del sector económico respectivo también debiesen ser consideradas, de modo que ciertas cláusulas que pudiesen ser estimadas como abusivas en el marco de contratos de consumo, por ejemplo, la asunción de los riesgos del caso fortuito, serán válidas en contratos celebrados entre profesionales de ciertos sectores de la economía. ${ }^{41}$ Por ello, la regulación de esta materia en contratos entre profesionales debiese descartar el uso de "listas negras", es decir, cláusulas prohibidas o que se consideren sin excepción como abusivas. ${ }^{42}$

\footnotetext{
${ }^{38}$ El art. II.- 9:405 del DCFR dispone: "Meaning of "unfair" in contracts between businesses. A term in a contract between businesses is unfair for the purposes of this Section only if it is a term forming part of standard terms supplied by one party and of such a nature that its use grossly deviates from good commercial practice, contrary to good faith and fair dealing”. Por su parte, el art. 86 de la CESL dispone: "Significado del término «abusivo» en los contratos entre comerciantes. 1. Una cláusula incluida en un contrato celebrado entre comerciantes será abusiva a efectos de la presente sección solo si: (a) forma parte de cláusulas no negociadas individualmente a tenor del artículo 7; y (b) resulta de tal naturaleza que su aplicación se aparta manifiestamente de las buenas prácticas comerciales, en contra de las exigencias de la buena fe contractual. 2. A efectos de la presente sección, a la hora de evaluar si una cláusula contractual resulta abusiva, deberá atenderse a: (a) la naturaleza de lo que se proporciona a través del contrato; (b) las circunstancias concurrentes en el momento en que se celebró; (c) el resto de las cláusulas contractuales; y (d) las cláusulas de cualquier otro contrato del cual dependa".

${ }^{39}$ JANSEN, cit. (n. 35).

${ }^{40}$ Schulte-Nolke, Hans, "No Market for 'Lemons': On the Reasons for a Judicial Unfairness Test for B2B Contracts", European Review of Private Law, 2-2015.

${ }^{41}$ Lehman, Matthias y Ungerer, Johannes, "Save the 'Mittelstand': How German Courts Protect Small and Medium-Sized Enterprises from Unfair Terms", European Review of Private Law, 2-2017. Así lo dispone, por ejemplo, el §301 I del Código Civil alemán, que al regular las condiciones generales de la contratación, que exige tener en consideración los usos y costumbres vigentes en el tráfico empresarial respectivo.

${ }^{42}$ El Código Civil alemán excluye expresamente la aplicación de los listados de cláusulas absoluta y relativamente prohibidas ( $\$ 308$ y $\S 309)$ a los contratos celebrados entre empresarios.
} 
En suma, las normas o hipótesis generales que contempla la legislación chilena para el control de cláusulas abusivas entre profesionales, deben aplicarse tomando en cuenta la especial naturaleza de tales contratos, sin que se utilicen los mismos criterios que se emplean para la determinación de la abusividad en contratos de consumo. En particular, en lo referido a los contratos agrícolas, no pueden obviarse los usos o costumbres de dicho mercado, la entidad y naturaleza de los contratantes (si son micro o pequeñas empresas, etc.) y en definitiva, las demás cláusulas del contrato o incluso otros contratos celebrados entre las partes, que podrían justificar que el productor agrícola renuncie a ciertos derechos o conceda ciertas ventajas a su comprador.

\section{CONCLUSIONES}

La cadena de suministro agrícola y alimentario es compleja, y en ella se presentan habitualmente situaciones de dependencia económica entre las partes que la integran, en particular, del productor agrícola respecto de su comprador. Ello puede derivar en distintas prácticas comerciales desleales y abusivas, entre ellas, la imposición de cláusulas abusivas por parte de los compradores. Al contrario de lo que sucede en el derecho europeo, el derecho chileno no se ha hecho cargo de este problema en particular, como tampoco, en general, de las cuestiones relativas a las cláusulas abusivas en contratos celebrados entre profesionales.

Como se explicó, para la hipótesis objeto de este trabajo, en que el productor agrícola actúa como proveedor (vende sus productos), no es posible extender el ámbito de aplicación de las normas de la Ley $\mathrm{N}^{\circ} 19.496$, ya que la Ley $\mathrm{N}^{\mathrm{o}} 20.146$ requiere que la micro o pequeña empresa celebre un contrato con un proveedor.

Sin embargo, existen otras normas contenidas en leyes especiales que podrían utilizarse para el control de estas cláusulas en materia de contratación agrícola, como los arts. 2 de la Ley Nº19.983 y 4 i) de la Ley No20.169. La aplicación de estas normas requiere superar algunos inconvenientes interpretativos, como la falta de delimitación de su ámbito de aplicación subjetivo (las empresas a las cuales se aplica) y objetivo (los contratos respecto de los cuales se aplica).

La correcta interpretación de tales normas, tanto para la contratación agrícola como para otros contratos celebrados entre profesionales, implica 
limitar las hipótesis de abusividad que ellas contemplan, a aquellas cláusulas no negociadas por las partes, y que puedan considerarse abusivas aplicando criterios más exigentes que los que se han desarrollado para la contratación de consumo, teniendo siempre en consideración que el propósito de la regulación de las cláusulas abusivas es la protección de aquella parte que se encuentra en una situación de asimetría o desventaja estructural respecto de la otra.

\section{BIBLIOGRAFÍA CITADA}

\section{a) Doctrina}

Campos, Sebastián, Control de contenido y régimen de ineficacia de las cláusulas abusivas, Thomson Reuters, Santiago, 2019

Cerpa, Javier y Farías, Claudio, "Uso de contratos en la agroindustria nacional para hortalizas", Oficina de Estudios y Políticas Agrarias - ODEPA, Ministerio de Agricultura, noviembre de 2020, disponible en: https://www.odepa. gob.cl/publicaciones/articulos/uso-de-contratos-en-la-agroindustria-nacionalpara-hortalizas.

Daskalova, Victoria, "The New Directive on Unfair Trading Practices in Food and EU Competition Law: Complementary or Divergent Normative Frameworks?", Journal of European Competition Law \& Practice, 2019, Vol. 10, No. 5

Daskalova, Victoria, "Regulating Unfair Trading Practices in the EU Agri-food Supply Chain: a Case of Counterproductive Regulation?", Yearbook of Antitrust And Regulatory Studies, 2020, Vol. 13 (21).

De la MazA, Iñigo, "El control de las cláusulas abusivas y la letra g)", Revista Chilena de Derecho Privado, 2004, Nº1.

Deshayes, Olivier; Genicon, Thomas y Laithier, Yves-María, Réforme du droit des contrats, du régime général et de la preuve des obligations, LexisNexis, Paris, 2016

Hesselink, Martjin, "Unfair terms in contracts between businesses", en: Schulze, R.; Stuyck, J. (Eds.), Towards a European Contract Law, Sellier, Munich, 2011

Jansen, Nils, "Section 2: Unfair Contract Terms", en: JANSEn, N.; Zimmermann, R. (Eds.), Commentaries on European Contract Laws, Oxford University Press, Oxford, 2018.

Lehman, Matthias; Ungerer, Johannes, "Save the 'Mittelstand': How German Courts Protect Small and Medium-Sized Enterprises from Unfair Terms", European Review of Private Law, 2017, $\mathrm{N}^{\circ} 2$.

López, Jorge y Elorriaga, Fabián, Los contratos. Parte general, Thomson 
Reuters, Santiago, 2017, 6a ed. actualizada.

Mato, María Natalia, Cláusulas abusivas y empresario adherente, Agencia Estatal Boletín Oficial del Estado, Madrid, 2017

Momberg, Rodrigo, "La transformación de la Ley de Protección de los Derechos de los Consumidores en la norma común del derecho de contratos chileno", en: Elorriaga, F. (Coord.), Estudios de Derecho Civil VII. Lexis Nexis, Santiago, 2012

Momberg, Rodrigo; Pizarro, Carlos, "Art. 16 g)”, en: De la Maza I.; PizArro, C. (Eds.), La protección de los derechos de los consumidores, Thomson Reuters, Santiago, 2013.

MomberG, Rodrigo, "Las personas jurídicas como consumidores", en: Ferrante, A. (Dir.), Venta y protección del consumidor, Thomson Reuters, 2019.

MomberG, Rodrigo, "El control de las cláusulas abusivas en contratos entre profesionales en el derecho chileno", en: Elorriaga, F. (Ed.), Estudios de Derecho Civil XV, Thomson Reuters, Santiago, 2021.

Morales, María Elisa; Mendoza, Pamela; Munita, Renzo, "Cláusulas abusivas entre empresas. Evolución en los principales sistemas de derecho comparado" Vniversitas, 2020 (69).

Schulte-Nolke, Hans, "No Market for 'Lemons': On the Reasons for a Judicial Unfairness Test for B2B Contracts", European Review of Private Law, 2015, 2.

The Supply Chain Initiative (Eds.), "Principles of Good Practice in vertical relationships in the Food Supply Chain", documento en línea: https:// www.supplychaininitiative.eu/about-initiative/principles-good-practice-verticalrelationships-food-supply-chain, consultada: 18 de febrero de 2021.

\section{b) Normativa}

Código Civil (Alemania).

Código Civil (Francia).

Ley $N^{\circ}$ 19.496, Protección de los derechos de los consumidores, 1997

Ley $\mathrm{N}^{\mathrm{o}} 19.983$, Regula la transferencia y otorga merito ejecutivo a copia de la factura, 2004

Ley No 20.169, Regula la competencia desleal, 2007 2010

Ley $\mathrm{N}^{\mathrm{o}} 20.416$, Fija normas especiales para las empresas de menor tamaño,

Ley N N 20.797, Crea el Registro Voluntario de Contratos Agrícolas, 2014.

Ley 12/2013, de medidas para mejorar el funcionamiento de la cadena alimentaria (España)

Directiva (UE) 2019/633 de 17 de abril de 2019, relativa a las prácticas comerciales desleales en las relaciones entre empresas en la cadena de suministro agrícola y alimentario (Unión Europea) 